\title{
Position Tracking Control of PMSM Based on Fuzzy PID-Variable Structure Adaptive Control
}

\author{
Pei Pei $\mathbb{D}$, Zhongcai Pei, Zhiyong Tang $\mathbb{D}$, and Han Gu $\mathbb{D}$ \\ School of Automation Science and Electrical Engineering, Beihang University, Beijing 100191, China \\ Correspondence should be addressed to Zhiyong Tang; zyt_76@buaa.edu.cn
}

Received 29 May 2018; Revised 14 August 2018; Accepted 7 September 2018; Published 30 September 2018

Guest Editor: Carlos Llopis-Albert

Copyright (C) 2018 Pei Pei et al. This is an open access article distributed under the Creative Commons Attribution License, which permits unrestricted use, distribution, and reproduction in any medium, provided the original work is properly cited.

\begin{abstract}
A novel Fuzzy PID-Variable Structure Adaptive Control is proposed for position tracking of Permanent Magnet Synchronous Motor which will be used in electric extremity exoskeleton robot. This novel control method introduces sliding mode variable structure control on the basis of traditional PID control. The variable structure term is designed according to the sliding mode surface which is designed by system state equation, so it could compensate for the disturbance and uncertainty. Considering the chattering of sliding mode system, the fuzzy inference method is adopted to adjust the parameters of PID adaptively in real time online, which can attenuate chattering and improve control precision and dynamic performance of system correspondingly. In addition, compared with the traditional sliding mode control, this method takes the fuzzy PID control item to replace the equivalent control item of sliding mode variable structure control, which could avoid the control performance reduction resulted from modeling error and parameter error of system. It is proved that this algorithm can converge to the sliding surface and guarantee the stability of system by Lyapunov function. Simulation results show that Fuzzy PID-Variable Structure Adaptive Control enjoys better control precision and dynamic performance compared with traditional control method, and it improves the robustness of system significantly. Finally, the effectiveness and practicability of the algorithm are verified by the method of Rapid Control Prototyping on the semiphysical simulation test bench.
\end{abstract}

\section{Introduction}

Lower extremity exoskeleton system is a kind intelligent assist robot, which is wearable, combines the operator with machine, and could be used in medical and military fields wildly [1-3]. Accurate and fast trajectory tracking is one of the core issues of extremity exoskeleton robot $[4,5]$. Therefore, the high precision control of the extremity exoskeleton robot driven by Permanent Magnet Synchronous Motor (PMSM) is one of the core problems of robot control. Conventional PID control which has weak robustness is incapable of dealing with nonlinear control, although it has the advantage of simple structure and easy implementation. PMSM is a multivariable and strongly coupled nonlinear system, thus having many factors in its control system, such as current coupling, system saturation, parameter perturbation, and external disturbance, which affect the performance of system directly [6]. Therefore, designing a control method with strong robustness, good dynamic performance, high control precision, and easy engineering implementation is the focus of research.

Sliding Mode Cotrol (SMC) is widely used as a nonlinear control method currently. By designing the sliding mode surface reasonably, the control performance of system will not be affected by internal parameter perturbation and external disturbance, and the system will have strong robustness and high control precision. However, the equivalent control term of sliding mode control depends on the accuracy of system model and parameters, while in practical application, only an approximate mathematical model of motor can be obtained. And there are still some uncertain factors, such as parameter error and external interference, which will reduce the performance of the sliding mode control and even cause the instability of system [7]. To solve the problem that SMC cannot obtain the accurate model and parameters of system, some intelligent methods are introduced to compensate the equivalent control item. Reference [8] introduced neural network into the variable structure control to compensate 
for the lack of accurate system models and parameters and proposed a neural network controller online training method which was applied to the speed loop of electric drive and improved the adaptability and robustness greatly based on variable structure control. An adaptive fuzzy sliding mode control strategy was designed to compensate for the influence of nonlinear, disturbances, and uncertain parameters in asymmetric hydraulic cylinder position servo control system in [9]. In this paper, the uncertain factors of the models and parameters were treated as interference. In [10], by using the linear feedback RBF, the sliding mode controller was compensated, and the control effect was further improved. Reference [11] proposed a method that achieved good results combining fast terminal sliding mode (FTSM) with radial basis function (RBF), which was applied to the vector control of PMSM. The method of combining neural network control and sliding mode variable structure control was proposed in $[12,13]$ with the main idea of meeting the sliding mode condition by adjusting the gain coefficient of control law online. Simply introducing the intelligent control method will make the controller structure complicated, increase the cost of controlling, and reduce the usability of control system. An ideal controller is designed to strive to reach an optimal tradeoff between performance and complexity.

As is known, PID control is a simple, easy to implement, and widely used control method. In the face of the traditional SMC the accurate models and parameters of system cannot be obtained. It is natural to think of the combination of sliding mode variable structure control and PID control. In the design of sliding surface, the integral term was introduced to form a sliding surface which was similar to PID structure in [14]. Two novel methods, integral approach law and PIDlike approach law, were proposed in [15], to control ElectroHydraulic Actuator (EHA). Among these control methods, PID control was only introduced to design sliding surface; however, the controller also consists of equivalent control item based on mode of system. In [16], PID control and sliding mode variable structure control were combined to be variable structure PID control (VSPID). PID control was introduced to replace the variable structure coefficient in SMC, so that the VSPID became a strict nonlinear controller. However, there was a risk that only nonlinear control cannot guarantee the optimal performance of the system. A similar approach was proposed in [17], and due to the use of PID control instead of the variable structure factor, it is still a switch value control.

Since the variable structure control is introduced in the design of controller in this paper, the chattering caused by variable structure control must be considered. References $[18,19]$ put forward an adaptive fuzzy sliding mode controller, which realized the self-adaption of variable structure parameters and attenuated the chattering caused by sliding mode control. Reference [20] proposed a method of fuzzy reaching law for robot control system, which greatly attenuated the chattering of traditional sliding mode system and made the system achieve better control performance. In order to give full play to the performance of the variable structure control item, the fuzzy inference method is introduced to attenuate the chattering of the system by adaptively modifying the parameters of PID. Since fuzzy PID control is a mature control method applied in engineering, it does not make the control structure too complex.

In this paper, the Fuzzy PID-Variable Structure Adaptive Control, which is mutual compensation of sliding mode variable structure control and fuzzy PID control, is proposed for trajectory tracking of PMSM used in extremity exoskeleton system. Firstly, this algorithm ensures stability of system by PID control instead of equivalent control. Then, a sliding mode surface based on state equation of system is designed for sliding mode variable structure control which compensates for insensitivity of PID control to parameter perturbations and external disturbances. Finally, the fuzzy reasoning method is added to adjust the parameters of PID adaptively online in real time, which improves robustness of system again and attenuates chattering of sliding mode system as well.

\section{Mathematical Model of PMSM}

The mathematical model of PMSM in the rotating shaft $(d, q)$ is

$$
\begin{aligned}
& \dot{i_{d}}=-\frac{R_{s}}{L} i_{d}+p_{n} \omega i_{q}+\frac{u_{d}}{L} \\
& \dot{i_{q}}=-p_{n} \omega i_{q}-\frac{R_{s}}{L} i_{d}-\frac{p_{n} \psi_{f}}{L} \omega+\frac{u_{q}}{L} \\
& \dot{\omega}=\frac{p_{n} \psi_{f}}{J} i_{q}-\frac{B}{J} \omega-\frac{T_{L}}{J} \\
& \dot{\theta}=\omega,
\end{aligned}
$$

where $u_{d}$ and $u_{q}$ are voltage component of $\mathrm{d}$ axis and $\mathrm{q}$ axis of the stator, respectively $(V), i_{d}$ and $i_{q}$ are current component of $\mathrm{d}$ axis and $\mathrm{q}$ axis of the stator, respectively $(A)$, $R_{s}$ is the resistance of stator winding $(\Omega), \psi_{f}=\sqrt{3 / 2} \psi_{f m}$ is electronic flux linkage, $L=L_{d}=L_{q}$ is the inductance of motor, $B$ is friction coefficient proportional to rotational speed, $T_{L}$ is load torque $(N . m), J$ is moment of inertia $\left(\mathrm{kg} \cdot \mathrm{m}^{2}\right), \theta=\theta_{e} / p_{n}$ is mechanical angle position of motor rotor $(\mathrm{rad})$, and $\omega=\omega_{e} / p_{n}$ is mechanical angle velocity of motor rotor $(\mathrm{rad} / \mathrm{s})$.

PMSM servo system is a three-closed-loop control system based on flux orientation, including position control loop, speed control loop, and current control loop. The threeclosed-loop control of PMSM is shown in Figure 1 while $i_{d}=0$. Besides PMSM, the system also includes a SVPWM inverter, a power rectifier, a position sensor, a current controller (ACR), a speed controller (ASR), and a position controller (APR). The position controller (APR) is our focus; meanwhile the speed controller (ASR) and the position controller (APR) are designed based on the traditional PID algorithm.

In order to design the position loop controller conveniently, it is assumed that the speed control loop, the current control loop, and the inverter are ideal. Therefore, 


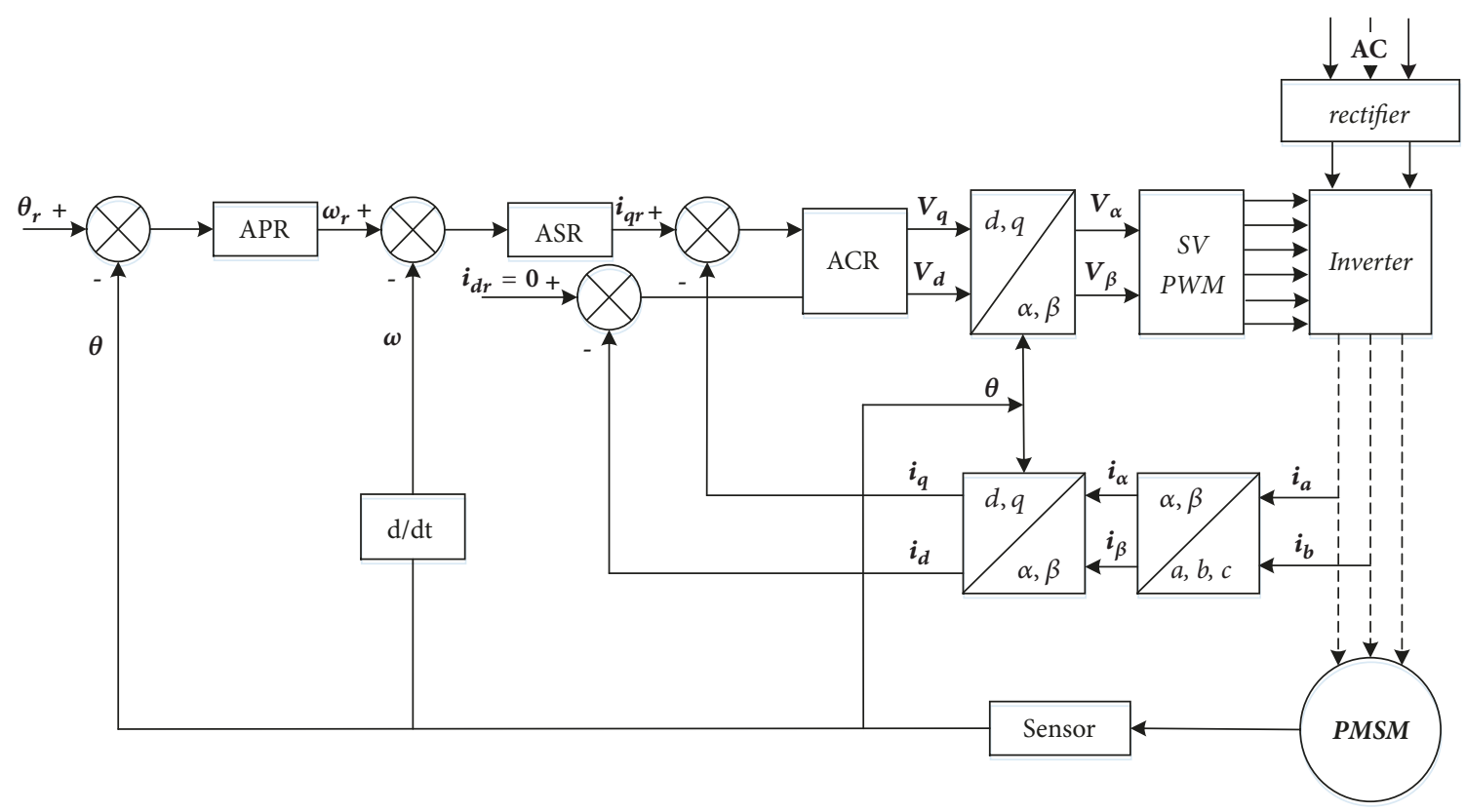

FIgure 1: Control schematic of PMSM.

the mathematical model of the PMSM can be simplified as a second-order differential link [21] as

$$
\begin{aligned}
& \dot{\theta}=\omega \\
& \dot{\omega}=\frac{p_{n} \psi_{f}}{J} i_{q}-\frac{B}{J} \omega-\frac{T_{L}}{J} .
\end{aligned}
$$

It can be also expressed as

$$
\ddot{\theta}=\frac{p_{n} \psi_{f}}{J} i_{q}-\frac{B}{J} \dot{\theta}-\frac{T_{L}}{J} .
$$

Let $p_{n} \psi_{f} / J=f,-B / J=g,-T_{L} / J=d$, and $i_{q}=u$. Then (3) can be simplified as

$$
\ddot{\theta}=g \dot{\theta}+f u+d,
$$

where $u$ represents the control input parameter.

The control target of the PMSM position loop is to enable the output to track the reference value quickly and accurately. Let $\mathrm{e}=\theta_{r}-\theta=e_{1}, \dot{e}=\dot{\theta}_{r}-\dot{\theta}=e_{2}$; then the state equation of the PMSM can be expressed as

$$
\begin{aligned}
& \dot{e_{1}}=e_{2} \\
& e_{2}=\dot{\theta_{r}}-\dot{\theta} .
\end{aligned}
$$

\section{Design of Fuzzy PID-Variable Structure Adaptive Controller}

3.1. Design of Fuzzy PID Controller. The fuzzy PID controller is designed as a system with two-dimensional input and three-dimensional output. The inputs are the error $(e)$ and the error change rate $\left(e_{c}\right)$ of system. The output $\left(\Delta K_{p}, \triangle K_{i}\right.$, and
$\left.\Delta K_{d}\right)$ is parameters compensation of PID controller. The PID parameters in practical applications can be expressed as

$$
\begin{gathered}
K_{P}=K_{p}{ }^{\prime}+\Delta K_{p} \\
K_{i}=K_{i}{ }^{\prime}+\Delta K_{i} \\
K_{d}=K_{d}{ }^{\prime}+\Delta K_{d},
\end{gathered}
$$

where $K_{p}{ }^{\prime}, K_{i}{ }^{\prime}$, and $K_{d}{ }^{\prime}$ are the preset parameter values of PID controller.

The control principle of fuzzy PID control is shown in Figure 2.

The core of fuzzy PID is the design of fuzzy inference rules. Firstly, fuzzify the input variables $e$ and $e_{c}$ by membership function, and then the inference is carried out according to predefined fuzzy rules. Finally, the barycenter method is used to defuzzify the reasoning results to achieve dynamic real-time update of PID parameters.

The fuzzy subset of two-dimensional input variables and three-dimensional output variables is defined as

$$
\{N B, N M, N S, Z O, P S, P M, P B\} \text {. }
$$

The same membership function is applied to the input variables and the output variables for real-time calculation and online adjustment. The membership functions $N B$ and $P B$ adopt Gaussian distribution function, while the rest adopt triangular distribution function [22], as is shown in Figure 3.

The fuzzy rules of $\Delta K_{p}, \Delta K_{i}$, and $\Delta K_{d}$ are shown in Table 1, where the first column is the fuzzy rules of $\Delta K_{p}$, the second column is the fuzzy rules of $\triangle K_{i}$, and the third column is the fuzzy rules of $\triangle K_{d} .49$ fuzzy control rules can be obtained from Table 1, which will be adopted for fuzzy controller designing. 
TABLE 1: Fuzzy rules table.

\begin{tabular}{|c|c|c|c|c|c|c|c|c|c|c|c|c|c|c|c|c|c|c|c|c|c|}
\hline \multirow{2}{*}{ e } & \multicolumn{21}{|c|}{ ec } \\
\hline & & NB & & & NM & & & NS & & & $\mathrm{ZO}$ & & & PS & & & $\mathbf{P M}$ & & & PB & \\
\hline NB & PS & $\mathrm{PM}$ & $\mathrm{NB}$ & PS & $\mathrm{NB}$ & NB & $\mathrm{PB}$ & NB & $\mathrm{NB}$ & $\mathrm{PM}$ & $\mathrm{NB}$ & NM & $\mathrm{PM}$ & NB & NS & $\mathrm{ZO}$ & $\mathrm{NB}$ & $\mathrm{ZO}$ & $\mathrm{ZO}$ & $\mathrm{PM}$ & $\mathrm{ZO}$ \\
\hline NM & $\mathrm{PB}$ & PS & $\mathrm{NB}$ & $\mathrm{PB}$ & NM & NB & PB & $\mathrm{NM}$ & NM & PS & NM & NS & PS & $\mathrm{NM}$ & NS & $\mathrm{ZO}$ & $\mathrm{NM}$ & $\mathrm{ZO}$ & $\mathrm{ZO}$ & PS & $\mathrm{ZO}$ \\
\hline NS & $\mathrm{PM}$ & PS & NM & $\mathrm{PM}$ & NM & NM & $\mathrm{PM}$ & NM & NS & PS & NM & NS & $\mathrm{ZO}$ & NM & $\mathrm{ZO}$ & NS & $\mathrm{NM}$ & PS & NS & PS & PS \\
\hline $\mathrm{ZO}$ & $\mathrm{PM}$ & $\mathrm{ZO}$ & NM & PM & NS & NS & PS & NS & NS & $\mathrm{ZO}$ & NS & $\mathrm{ZO}$ & NS & NS & PS & NM & NS & $\mathrm{NM}$ & $\mathrm{NM}$ & $\mathrm{ZO}$ & $\mathrm{NM}$ \\
\hline PS & PS & $\mathrm{ZO}$ & NS & PS & $\mathrm{ZO}$ & NS & $\mathrm{ZO}$ & $\mathrm{ZO}$ & $\mathrm{ZO}$ & NS & $\mathrm{ZO}$ & PS & NS & $\mathrm{ZO}$ & PS & NM & $\mathrm{ZO}$ & $\mathrm{PM}$ & $\mathrm{NM}$ & $\mathrm{ZO}$ & $\mathrm{PM}$ \\
\hline PM & $\mathrm{ZO}$ & $\mathrm{PB}$ & $\mathrm{ZO}$ & $\mathrm{ZO}$ & PS & $\mathrm{ZO}$ & NS & PS & PS & NM & PS & PS & $\mathrm{NM}$ & PS & $\mathrm{PM}$ & NM & PS & PB & NB & PB & $\mathrm{PB}$ \\
\hline PB & $\mathrm{ZO}$ & $\mathrm{PB}$ & $\mathrm{ZO}$ & $\mathrm{ZO}$ & $\mathrm{PM}$ & $\mathrm{ZO}$ & NM & PM & $\mathrm{PM}$ & $\mathrm{NB}$ & $\mathrm{PM}$ & $\mathrm{PM}$ & NM & $\mathrm{PM}$ & $\mathrm{PM}$ & NB & $\mathrm{PM}$ & PB & NB & $\mathrm{PM}$ & $\mathrm{PB}$ \\
\hline
\end{tabular}

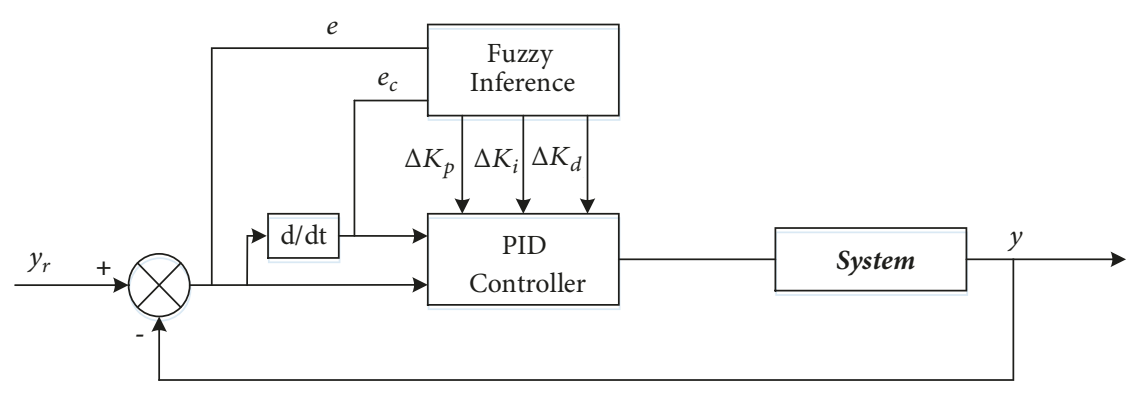

FIgUre 2: Control schematic of Fuzzy PID.

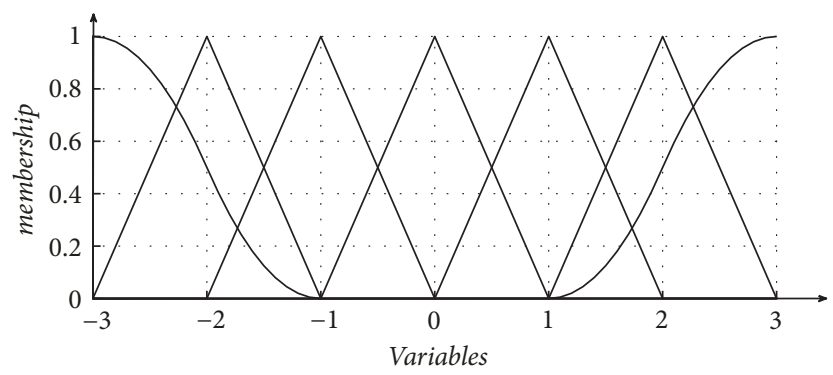

FIGURE 3: Membership function curve.

The process of adaptively adjusting PID parameters should follow the following principles:

(1) $K_{p}$ : When $e$ is a positive and larger value, $\Delta K_{p}$ is positive, that is, to increase $K_{p}$. However, when $e$ is negative and its absolute value is increasing, the system is in overshoot state, so $K_{p}$ should be reduced. When $e$ is near zero, if $e_{c}$ is negative, the system overshoot will become larger and larger, so $K_{p}$ should be reduced; if $e_{c}$ is positive, in order to reduce the deviation, $\triangle K_{p}$ should be positive.

(2) $K_{i}$ : Following the principle of integral separation, its regulation is similar to that of $K_{p}$, but the situation of integral saturation should be prevented, for fear of system overshoot. If $K_{p}$ increases, $K_{i}$ should be reduced accordingly.

(3) $K_{d}$ : When $e$ is positive and increasing, increasing $K_{p}$ may cause differential spillover. Therefore, if the larger $K_{p}$ is taken, the smaller $K_{d}$ should be taken.

Finally, the fuzzy quantity of the output variable is defuzzified as the output of the controller by barycenter method as

$$
u(t)=\frac{\sum_{i=1}^{n} u_{i} A\left(u_{i}\right)}{\sum_{i=1}^{n} A\left(u_{i}\right)},
$$

where $u_{i}$ is the ith element of $u$ and $A\left(u_{i}\right)$ is the $u_{i}$ th membership function of A on $u(t)$.

Then, the output of Fuzzy PID controller can be expressed as

$$
u_{P I D}=K_{p} e+K_{i} \int e+K_{d} \frac{d e}{d t}
$$

where $K_{P}=K_{p}{ }^{\prime}+\Delta K_{p}, K_{i}=K_{i}{ }^{\prime}+\Delta K_{i}$, and $K_{d}=K_{d}{ }^{\prime}+\Delta K_{d}$.

3.2. Design of Sliding Mode Variable Structure Controller. According to state equations (5), the sliding mode surface is defined as

$$
s=c e_{1}+e_{2}
$$

where $c$ is a positive constant. 


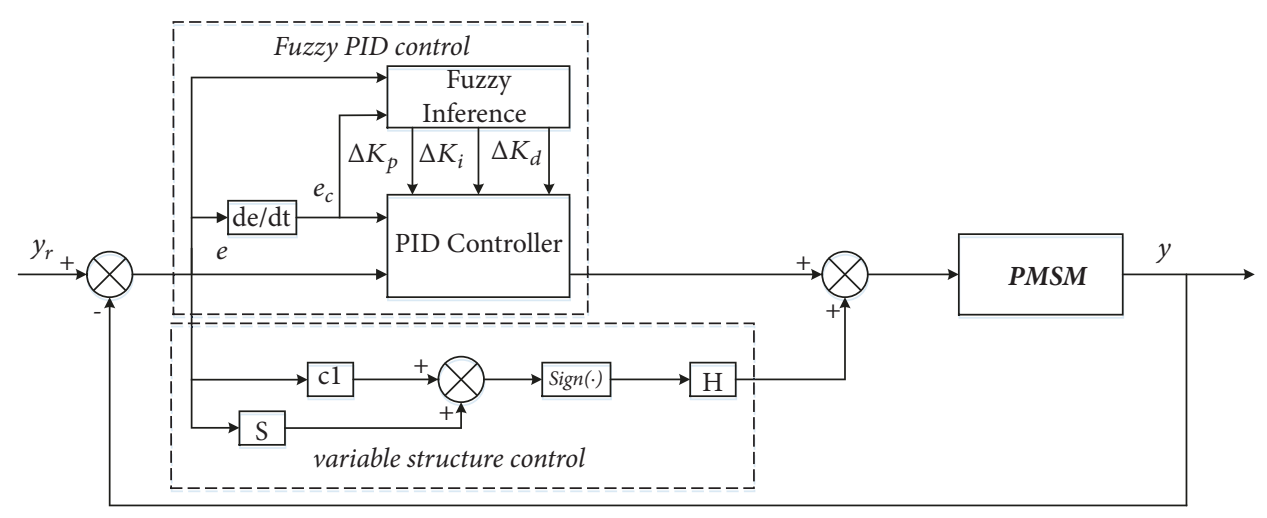

FIGURE 4: Control schematic of Fuzzy PID-Variable Structure Adaptive Control.

$s=\dot{s}=0$ can be obtained according to the condition that the system maintains the motion on the sliding surface. That is,

$$
\dot{s}=c \dot{e}+\ddot{e}=c \dot{e}+\left(\ddot{\theta}_{r}-\ddot{\theta}\right),
$$

where $\theta_{r}$ is the desired trajectory.

From (4), (10), and (11), we have

$$
u^{*}=\frac{1}{f}\left(c \dot{e}+\ddot{\theta_{r}}-g \dot{\theta}-d\right) .
$$

From (12), it can be seen that the result of equivalent control quantity $u^{*}$ includes $f, g$, and $d$. $f$ and $g$ are determined by the system parameters $B$ and $J . d$ is determined by the system parameters $J$ and $T_{L}$. It can be inferred that the equivalent control amount will be changed with system parameter perturbation and load disturbance, and then the input will make the moving point away from the sliding surface, which will even lead to negative effect on servo system.

The switch item should be designed as

$$
u_{r}=k \operatorname{sign}(s) \text {, }
$$

where $k>0$ is the variable structure gain; $s$ is the sliding mode surface; and sign $(\bullet)$ is the sign function.

3.3. Design of Fuzzy PID-Variable Structure Adaptive Controller. Considering that the equivalent control item in SMC will affect the servo control performance due to modeling error and inaccurate parameters of system, the effect of the equivalent control item in SMC is compensated by PID control item, and then the effect of the nonlinear is compensated by the variable structure control item. Meanwhile, the fuzzy inference method is used to adjust the parameters of PID in real time online, which can attenuate chattering. The fuzzy PID controller can ensure the stability of system, limit the error to a narrow range, and attenuate the chattering of SMC as well. On the other hand, the variable structure control item is used to compensate the effect of nonlinear, which can suppress the effect of parameter perturbation and load disturbance. The schematic diagram of Fuzzy PID-Variable Structure Adaptive Control is shown in Figure 4.
The output of Fuzzy PID-Variable Structure Adaptive Controller is

$$
\begin{aligned}
u= & {\left[\left(K_{p}{ }^{\prime}+\Delta K_{p}\right) e+\left(K_{i}{ }^{\prime}+\Delta K_{i}\right) \int e\right.} \\
& \left.+\left(K_{d}{ }^{\prime}+\Delta K_{d}\right) \frac{d e}{d t}\right]+h \operatorname{sign}(s),
\end{aligned}
$$

where $s$ is the sliding mode surface, $\left[\left(K_{p}{ }^{\prime}+\Delta K_{p}\right) e+\left(K_{i}{ }^{\prime}+\right.\right.$ $\left.\left.\Delta K_{i}\right) \int e+\left(K_{d}{ }^{\prime}+\Delta K_{d}\right)(d e / d t)\right]$ is the approximate linear control item, and $h \operatorname{sign}(s)$ is the nonlinear control item.

\section{Proof of Stability}

The controller designed by (14) is used to control PMSM position loop described in (4) and (5). If the control parameters are selected according to the constraints of (15), the system state can converge to the sliding surface and ensure global stability of the system.

$$
\begin{aligned}
\alpha_{3} & <g \alpha_{2}+f h+\alpha_{4} \\
f_{i} k_{d i} & >c_{i}+g_{i}+p_{i},
\end{aligned}
$$

where $\alpha_{1}, \alpha_{2}, \alpha_{3}$, and $\alpha_{4}$ are the upper bounds of given position target $\left(\theta_{r}\right)$, derivative of given position target $\left(\dot{\theta}_{r}\right)$, the second derivative of given position target $\left(\ddot{\theta}_{r}\right)$, and load disturbance $d$, respectively, and $p$ is the parameter of positive definite matrix defined later. It can be also expressed as

$$
\begin{aligned}
\left\|\theta_{r}\right\| & \leq \alpha_{1} \\
\left\|\dot{\theta}_{r}\right\| & \leq \alpha_{2} \\
\left\|\ddot{\theta}_{r}\right\| & \leq \alpha_{3} \\
\|d\| & \leq \alpha_{4},
\end{aligned}
$$

where $\|\bullet\|$ is the Euclidean norm.

In the actual control system, the position target input of the system is bounded, and the perturbation of system parameters and the disturbance of external load will change within a certain range. Thus the assumption in (16) is reasonable in the actual control system. 
For $n$-dimensional system the sliding surface can be expressed as

$$
\begin{aligned}
\mathrm{S} & =\left[\begin{array}{llll}
s_{1} & s_{2} & \ldots & s_{n}
\end{array}\right]^{T} \quad n=1,2 \ldots n \\
s_{i} & =c_{i} e_{1 i}+e_{2 i} .
\end{aligned}
$$

The control item in (13) can be expressed as

$$
U=\left(K_{P} E+K_{I} \int E+K_{D} \frac{d E}{d t}\right)+H \operatorname{sign}(S) .
$$

To construct a control matrix for an $n$-dimensional system reasonably, set

$$
\begin{aligned}
K_{P} & =\operatorname{diag}\left\{\begin{array}{llll}
K_{p 1} & K_{p 2} & \ldots & K_{p n}
\end{array}\right\} \\
K_{I} & =\operatorname{diag}\left\{\begin{array}{llll}
K_{i 1} & K_{i 2} & \ldots & K_{i n}
\end{array}\right\} \\
K_{D} & =\operatorname{diag}\left\{\begin{array}{llll}
K_{d 1} & K_{d 2} & \ldots & K_{d n}
\end{array}\right\} \\
E & =\left[\begin{array}{llll}
e_{1} & e_{2} & \ldots & e_{n}
\end{array}\right]^{T} \\
H & =\operatorname{diag}\left\{\begin{array}{llll}
h_{1} & h_{2} & \ldots & h_{n}
\end{array}\right\} \\
\operatorname{sign}(S) & =\operatorname{diag}\left\{\operatorname{sign}\left(s_{1}\right) \operatorname{sign}\left(s_{2}\right) \ldots \operatorname{sign}\left(s_{n}\right)\right\} .
\end{aligned}
$$

Construct a positive definite Lyapunov function as

$$
\mathrm{V}=\frac{S^{T} S}{2}+\frac{\left[\begin{array}{ll}
E^{T} & \dot{E^{T}}
\end{array}\right]\left[\begin{array}{ll}
Q & P \\
P & G
\end{array}\right]\left[\begin{array}{c}
E \\
\dot{E}
\end{array}\right]}{2} \text {. }
$$

In order to guarantee the positive definiteness of the Lyapunov function (21), the definition of the symmetry matrix $\left[\begin{array}{ll}Q & P \\ P & G\end{array}\right]$ is

$$
\begin{aligned}
& Q=\operatorname{diag}\left(\begin{array}{llll}
q_{1} & q_{2} & \ldots & q_{n}
\end{array}\right) \\
& P=\operatorname{diag}\left(\begin{array}{llll}
p_{1} & p_{2} & \ldots & p_{n}
\end{array}\right) \\
& G=\operatorname{diag}\left(\begin{array}{llll}
g_{1} & g_{2} & \ldots & g_{n}
\end{array}\right),
\end{aligned}
$$

where $q_{i}, p_{i}$, and $g_{i}$ satisfy the following relationship:

$$
c_{i}^{2}-c_{i} f_{i} k_{d i}+c_{i} g_{i}-f_{i} k_{p i}+q_{i}=0 .
$$

Differentiating $V$, we obtain

$$
\begin{aligned}
\dot{V} & =S^{T} \dot{S}+\left[\begin{array}{ll}
E^{T} & \dot{E}^{T}
\end{array}\right]\left[\begin{array}{ll}
Q & P \\
P & G
\end{array}\right]\left[\begin{array}{c}
\dot{E} \\
\ddot{E}
\end{array}\right] \\
& =\sum_{i=1}^{n}\left(s \dot{s}+q_{i} e_{1 i} e_{2 i}+p_{i} e_{2 i}{ }^{2}\right) .
\end{aligned}
$$

From (4), (5), (11), and (14), (25) can be obtained:

$$
\begin{aligned}
\dot{s}_{i}= & \ddot{\theta_{r i}}-g_{i} \dot{\theta_{r i}}-f_{i} k_{p i} e_{1 i}+\left(c_{i}+g_{i}-f_{i} k_{d i}\right) e_{2 i} \\
& -f_{i} k_{i i} \int e_{1 i}-f_{i} h_{i} \operatorname{sign}\left(s_{i}\right)-d_{i} .
\end{aligned}
$$

In the process of stability analysis, as there is no integral term in the design of sliding mode surface, the integral term in fuzzy PID can be ignored. Then (26) can be obtained:

$$
\begin{aligned}
s_{i} \dot{s}_{i}= & \left(c_{i} e_{1 i}+e_{2 i}\right)\left[\ddot{\theta_{r i}}-g_{i} \dot{\theta_{r i}}-f_{i} h_{i} \operatorname{sign}\left(s_{i}\right)-d_{i}\right] \\
& -c_{i} f_{i} k_{p i} e_{1 i}{ }^{2} \\
& +\left(c_{i}{ }^{2}+c_{i} g_{i}-c_{i} f_{i} k_{d i}-f_{i} k_{p i}\right) e_{1 i} e_{2 i} \\
& +\left(c_{i}+g_{i}-f_{i} k_{d i}\right) e_{2 i}{ }^{2} .
\end{aligned}
$$

Substituting (26) into (24), the following equation can be obtained:

$$
\begin{aligned}
\dot{V} & =\sum_{i=1}^{n}\left\{\left(c_{i} e_{1 i}+e_{2 i}\right)\left[\ddot{\theta_{r i}}-g_{i} \dot{\theta_{r i}}-f_{i} h_{i} \operatorname{sign}\left(s_{i}\right)-d_{i}\right]\right. \\
& -c_{i} f_{i} k_{p i} e_{1 i}^{2}+\left(c_{i}+g_{i}-f_{i} k_{d i}+p_{i}\right) e_{2 i}^{2} \\
& \left.+\left(c_{i}^{2}+c_{i} g_{i}-c_{i} f_{i} k_{d i}-f_{i} k_{p i}+q_{i}\right) e_{1 i} e_{2 i}\right\} .
\end{aligned}
$$

Because of (23), we can obtain

$$
\begin{aligned}
\dot{V} & =\sum_{i=1}^{n}\left\{s_{i}\left[\ddot{\theta_{r i}}-g_{i} \dot{\theta_{r i}}-f_{i} h_{i} \operatorname{sign}\left(s_{i}\right)-d_{i}\right]\right. \\
& \left.-c_{i} f_{i} k_{p i} e_{1 i}{ }^{2}+\left(c_{i}+g_{i}-f_{i} k_{d i}+p_{i}\right) e_{2 i}{ }^{2}\right\} .
\end{aligned}
$$

Combining (16), then (28) can be expressed as

$$
\begin{aligned}
\dot{V} \leq & -\sum_{i=1}^{n}\left[\left\|s_{i}\right\|\left(g_{i} \alpha_{2}+f_{i} h_{i}+\alpha_{4}-\alpha_{3}\right)\right] \\
& -\sum_{i=1}^{n}\left[\left(c_{i} f_{i} k_{p i}\right) e_{1 i}^{2}\right] \\
& -\sum_{i=1}^{n}\left[\left(-c_{i}-g_{i}+f_{i} k_{d i}-p_{i}\right) e_{2 i}{ }^{2}\right] .
\end{aligned}
$$

It can be deduced that $\dot{V}$ is a negative definite matrix when (15) is satisfied. According to Lyapunov's second method, it can be concluded that the system is globally stable based on Fuzzy PID-Variable Structure Adaptive Control.

\section{Simulation Verification}

The model of the position-speed-current three-closed-loop control system for PMSM vector control is built based on Matlab/Simulink. The speed loop and the current loop adopt the conventional PID control while the position loop adopts the Fuzzy PID-Variable Structure Adaptive Control which is introduced in this paper. The simulation model is shown in Figure 5.

The parameters of the simulation model are shown in Table 2 .

Figures 6-10 show the step response. The input reference position is a step signal of $\theta_{r}=0.6(\mathrm{rad})$, and the load disturbance of $50 \mathrm{Nm}$ is added at $0.75 \mathrm{~s}$. The simulation results 


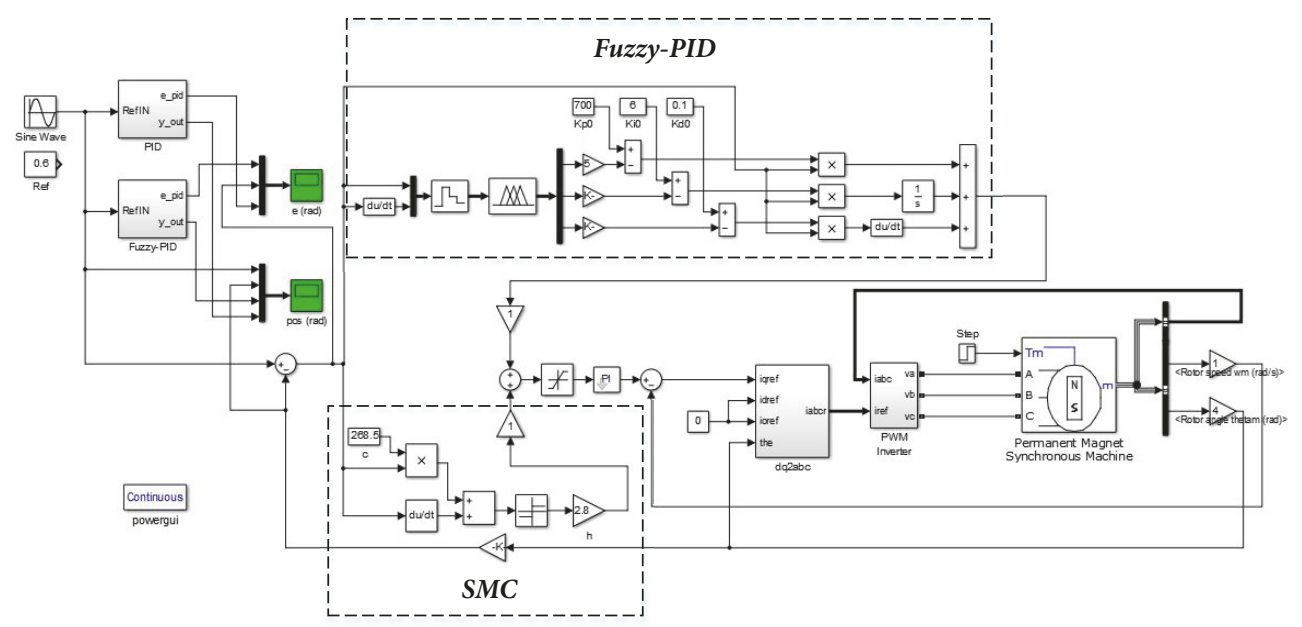

FIGURE 5: Simulink model.

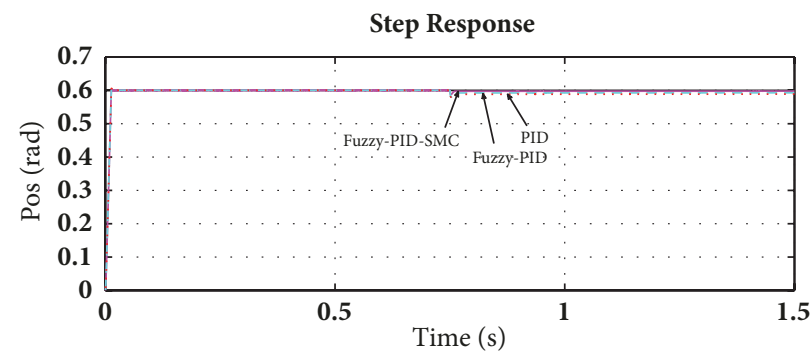

FIgURE 6: Step response (a).

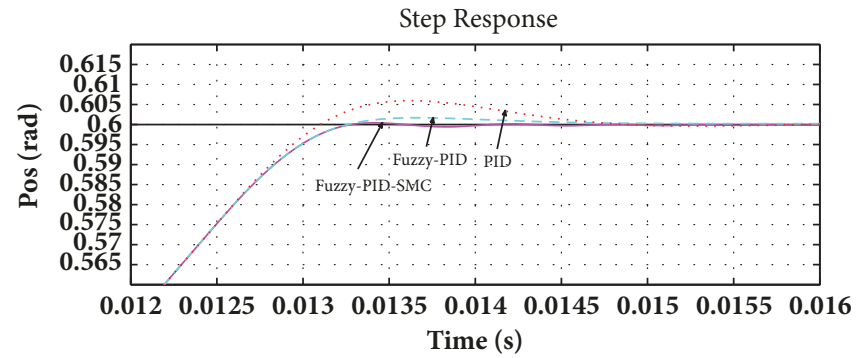

Figure 7: Step response (b).

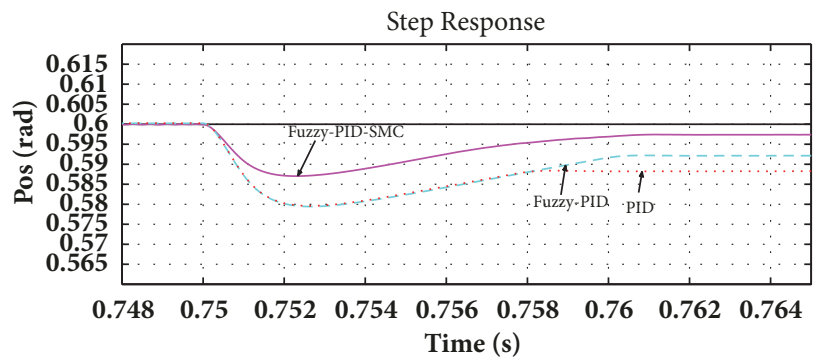

Figure 8: Step response (c). 
TABLE 2: The parameters of the simulation model.

\begin{tabular}{lccc}
\hline Parameter & Value & Parameter & Value \\
\hline$R s$ & $2.875 \Omega$ & $K_{p 0}$ & 700 \\
$L$ & $0.00153 \mathrm{H}$ & $K_{i 0}$ & 6 \\
$\psi_{f}$ & $0.175 \mathrm{~Wb}$ & $K_{d 0}$ & 0.1 \\
$J$ & $0.0008 \mathrm{Kgm}^{2}$ & $c$ & 268.5 \\
$P_{n}$ & 4 & $h$ & 2.8 \\
$K_{T}$ & 1.05 & & \\
\hline
\end{tabular}

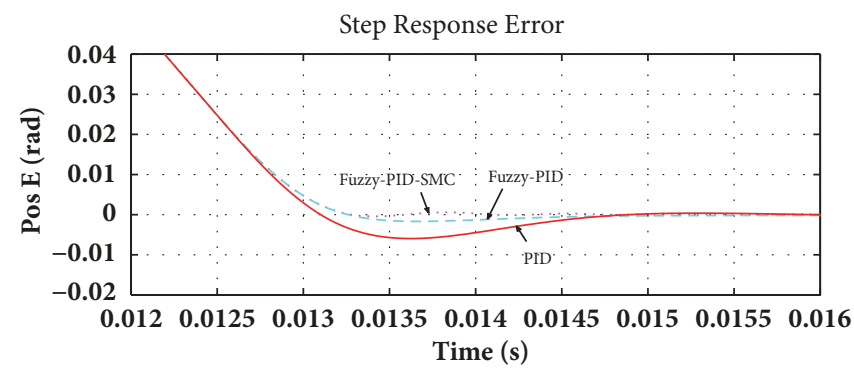

FIGURE 9: Step response error (a).

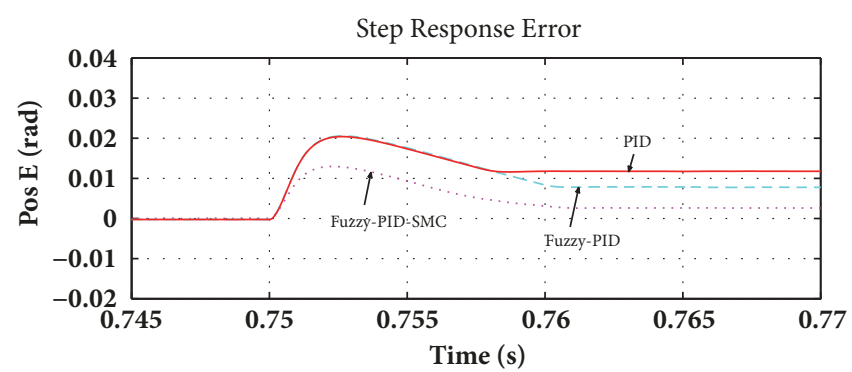

FIGURE 10: Step response error (b).

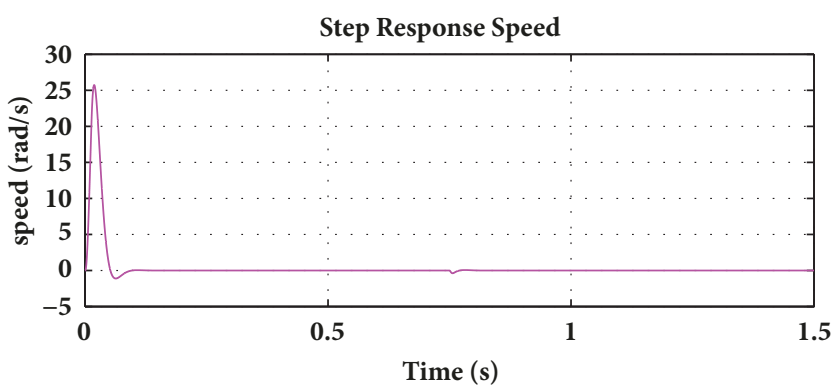

FIGURE 11: Step response speed under Fuzzy PID-Variable Structure Adaptive Control.

are compared with conventional PID control and fuzzy PID control.

From Figure 6, it can be seen that all the three control algorithms can obtain better results based on the condition that the parameters of the control system are appropriate. However, it can be seen from the details that compared with PID control and fuzzy PID control, the Fuzzy PIDVariable Structure Adaptive Control can accelerate system convergence, reduce system response time, and obtain better dynamic performance and robustness. Especially after adding load disturbances, the Fuzzy PID-Variable Structure Adaptive
Control responds fastest and converges to the reference position in the shortest time. In addition, the simulation results show that the chattering of variable structure control is attenuated obviously due to the adaptive adjustment of PID control parameters online. Figure 11 is the speed curve (after a low-pass filter) of PMSM controlled by Fuzzy PID-Variable Structure Adaptive Controller. Figure 12 shows the current curve (after a low-pass filter) of the $q$ axis (the deceleration ratio of 50 is considered).

Figures 13-15 show the sinusoidal response. The input reference position of system is a sinusoidal signal (amplitude: 


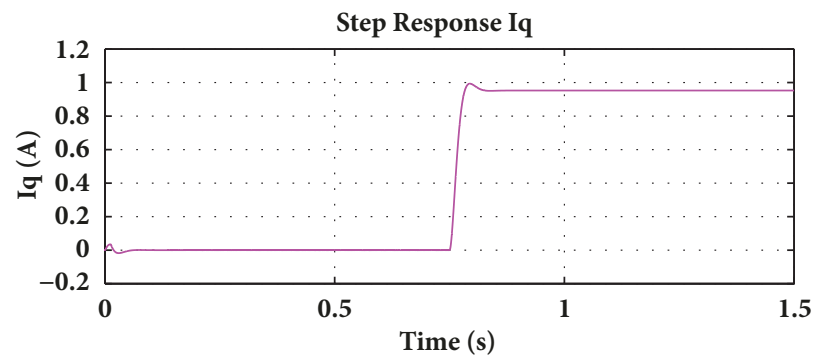

FIGURE 12: Step response $i_{q}$ under Fuzzy PID-Variable Structure Adaptive Control.

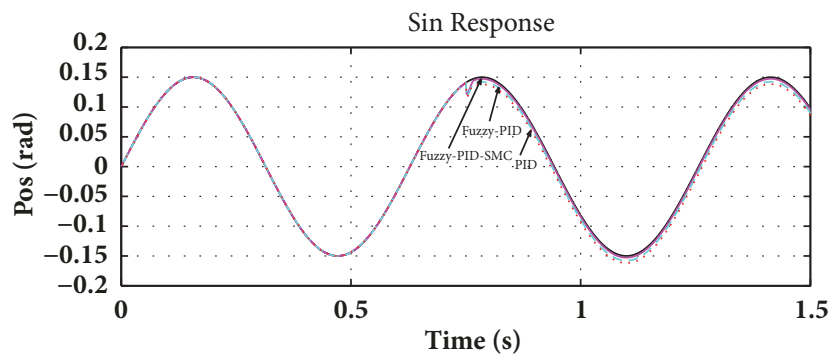

Figure 13: Sinusoidal response (a).

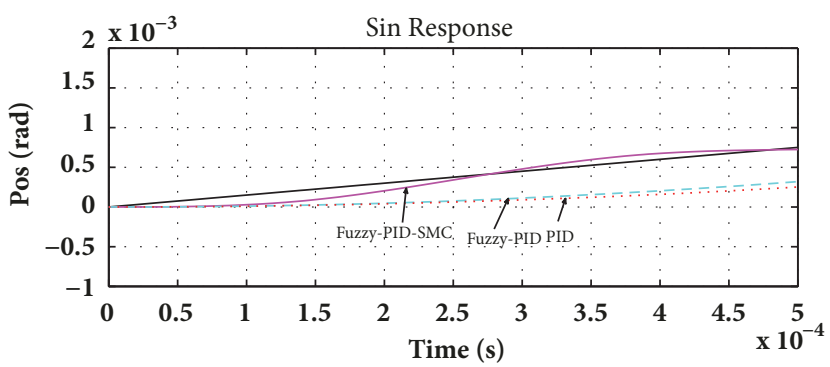

FIGURE 14: Sinusoidal response (b).

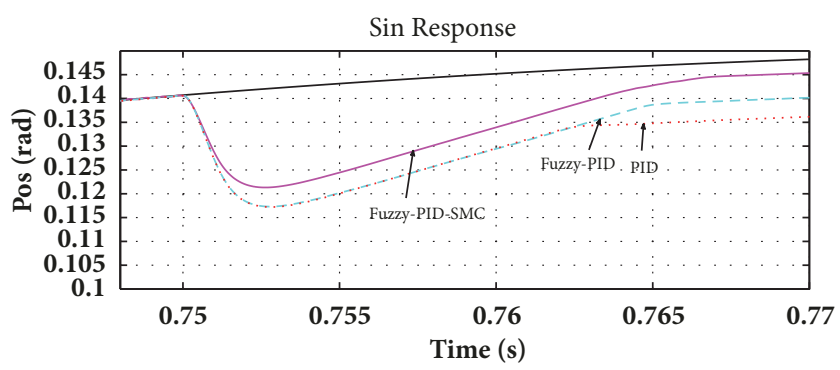

FIGURE 15: Sinusoidal response (c).

$0.15 \mathrm{rad}$, frequency: $10 \mathrm{~Hz}$ ), and the load disturbance of $50 \mathrm{Nm}$ is added at $0.75 \mathrm{~s}$. Compared with Fuzzy PID-Variable Structure Adaptive Control, the other two algorithms exhibit phase lag. Especially after adding load disturbance, PID control and fuzzy PID control exhibit a large static deviation. In addition, the simulation results show that the chattering of variable structure control is attenuated obviously due to the adaptive adjustment of PID control parameters online. Figure 16 is the speed curve (after a low-pass filter) of PMSM controlled by Fuzzy PID-Variable Structure Adaptive
Controller. Figure 17 shows the current curve (after a lowpass filter) of the $q$ axis (the deceleration ratio of 50 is considered).

By analyzing the step response and sinusoidal response with load disturbance, the Fuzzy PID-Variable Structure Adaptive Control can improve the servo precision, the dynamic performance, and the robustness of system. At the same time, the chattering of variable structure control is also attenuated obviously because the PID parameters can be adjusted online adaptively by fuzzy inference. 


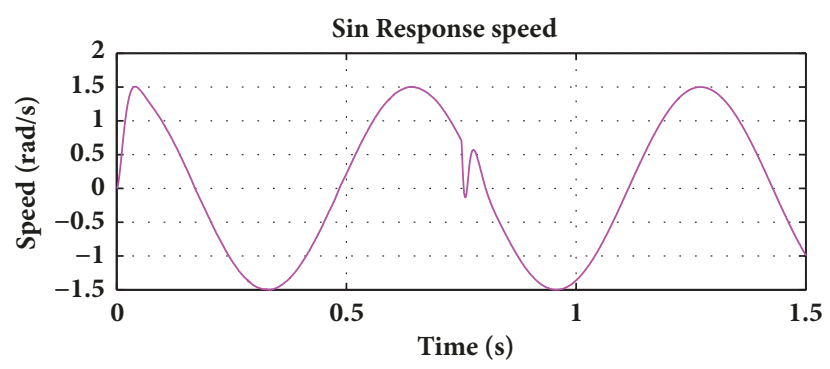

FIGURE 16: Sinusoidal response speed under Fuzzy PID-Variable Structure Adaptive Control.

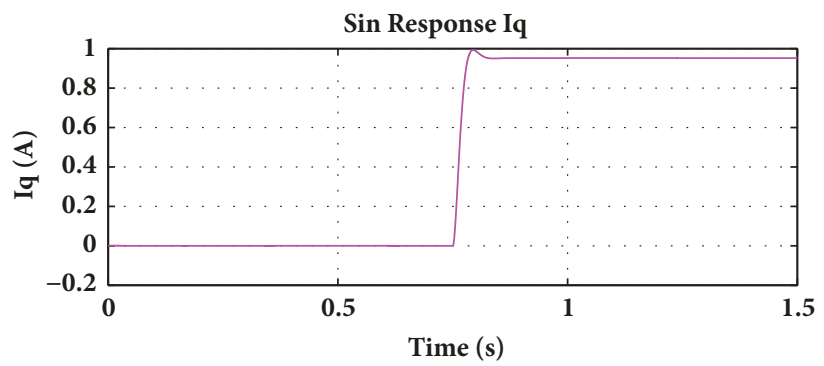

FIgUre 17: Sinusoidal Response $i_{q}$ under Fuzzy PID-Variable Structure Adaptive Control.

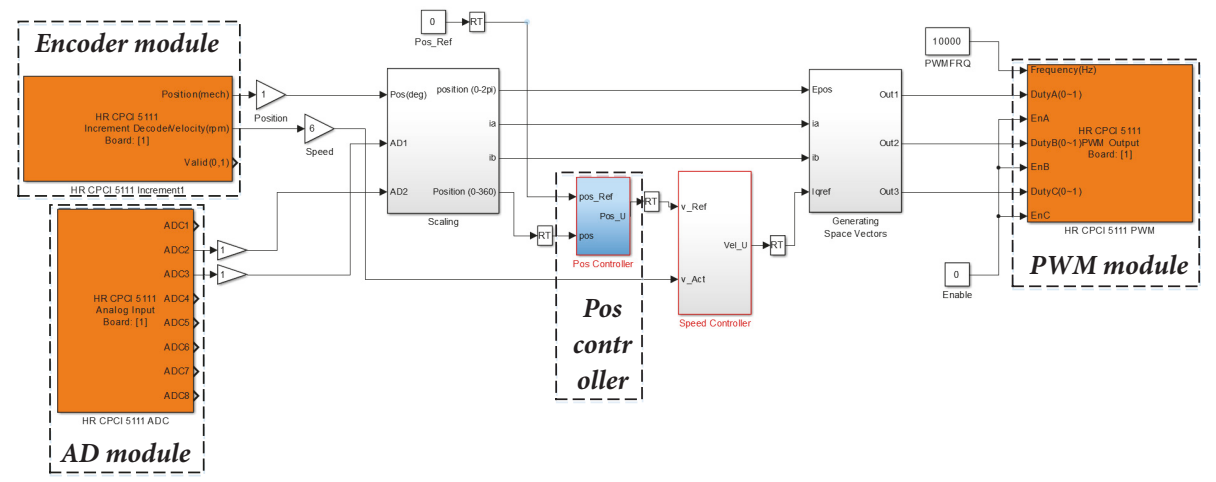

Figure 18: RCP model.

\section{Experiment Verification}

The Rapid Control Prototype (RCP) is a kind of semiphysical simulation. After the mathematical simulation of the system control model meets the desired effect, the control algorithm model of the servo system will be extracted individually. Then the Real-Time Driver (RTD) of actual controlled object, feedback original, and drive unit are added to the control algorithm, which will constitute a closed-loop system [23, 24]. Before the structure design and processing completion of extremity exoskeleton, the effectiveness of Fuzzy PIDVariable Structure Adaptive Control is verified on a semiphysical simulation test bench. The RCP model is shown in Figure 18.

The control system test bench is shown in Figure 19.

The control principle of test bench is shown in Figure 20.

6.1. Static Testing. The step response performances of conventional PID control and Fuzzy PID-Variable Structure
Adaptive Control are compared by a step signal. The step response testing is performed with a constant torque of $5 \mathrm{Nm}$, and the step motion mode is a reciprocating motion with the range of $100^{\circ}$ to $200^{\circ}$. The experimental results are shown in Figures 21-25; Figure 21 is the position tracking curve, Figure 22 is the position tracking error curve, and Figure 23 is the speed curve. Figure 24 is the original curve of torque sensor under Fuzzy PID-Variable Structure Adaptive Control (it is basically consistent with the curve of torque sensor under PID control), and Figure 25 is the curve of torque sensor after a low-pass filter.

It can be seen from Figures 21 and 22 that the positioning accuracy of conventional PID control and Fuzzy PID-Variable Structure Adaptive Control is almost the same. However, it is evident that the dynamic response of Fuzzy PID-Variable Structure Adaptive Control outperforms that of conventional PID control. Because of the unidirectional constant torque, the forward step response and reverse step response of the same control will be different. Through comparison, 


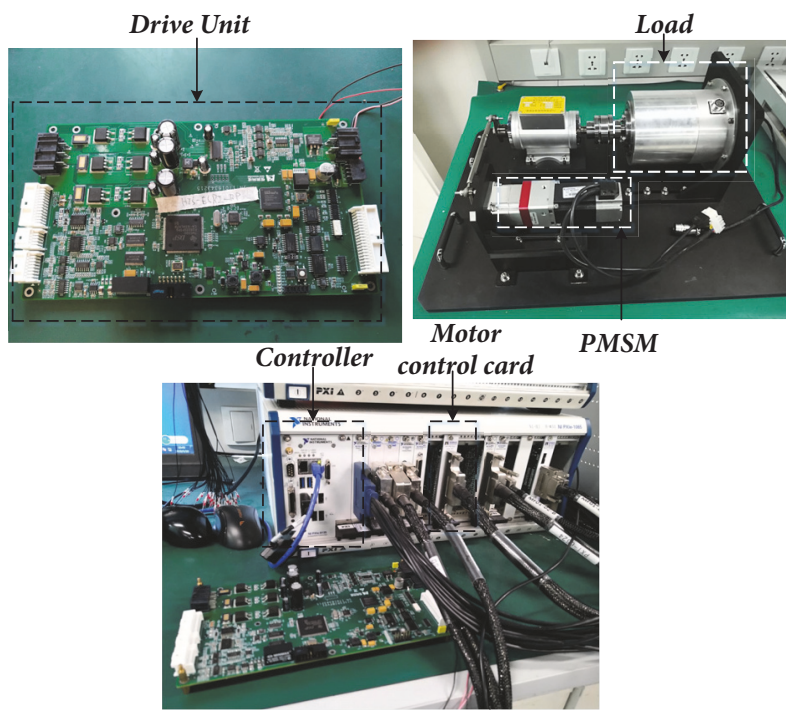

Figure 19: The control system test bench.

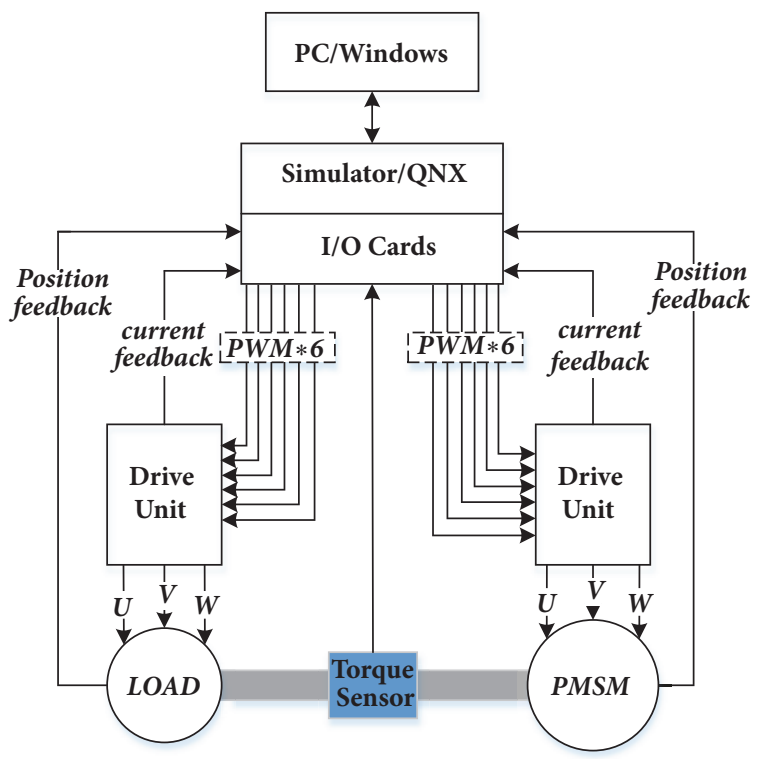

FIGURE 20: The control principle.

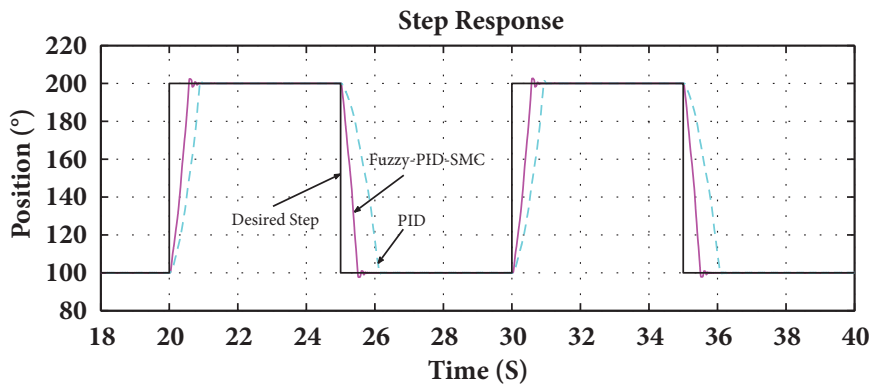

FIGURE 21: Step response position tracking. 


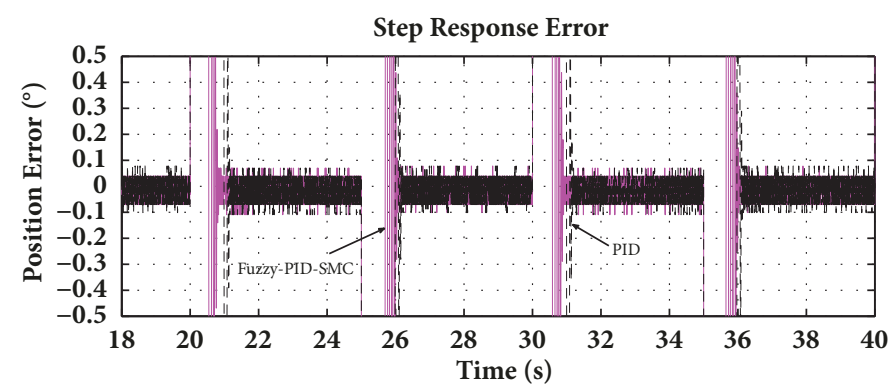

FIGURE 22: Step response position tracking error.

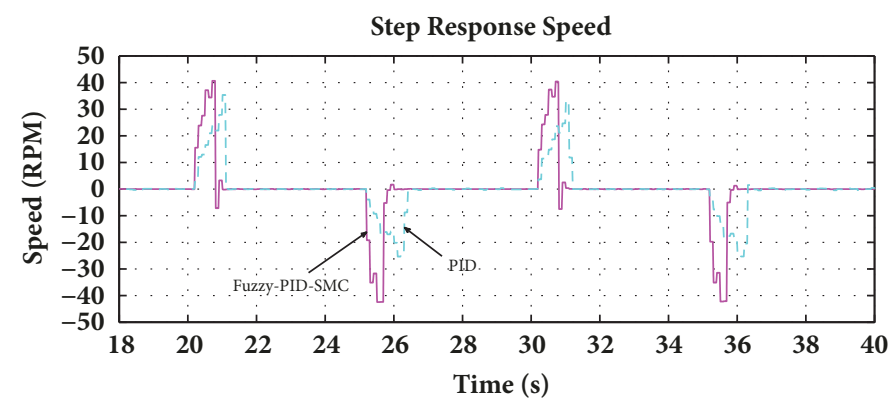

FIGURE 23: Step response speed.

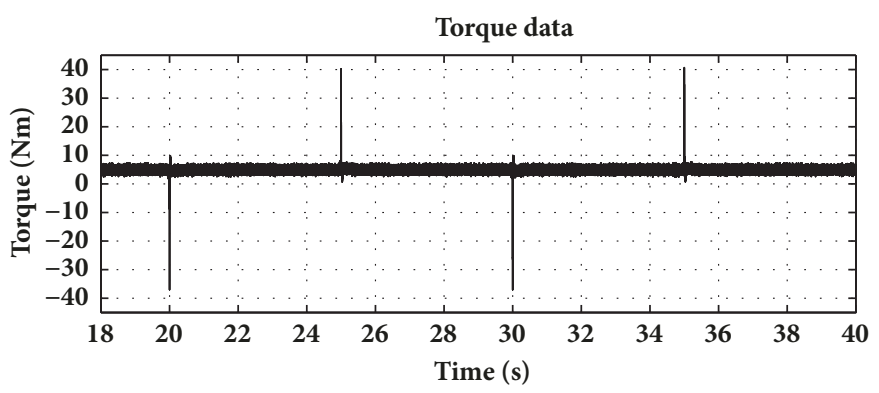

FIgURE 24: Step response original torque data.

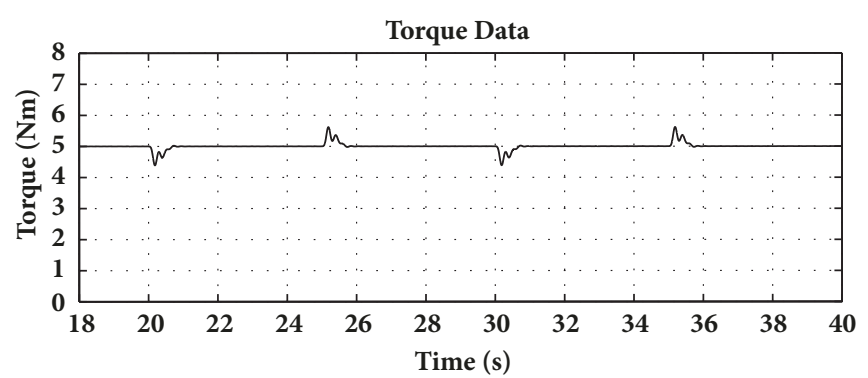

FIgURE 25: Step response torque data after low-pass filter.

it is observed that the forward step response and reverse step response under Fuzzy PID-Variable Structure Adaptive Control are more consistent.

6.2. Dynamic Testing. The dynamic response performances of conventional PID control and Fuzzy PID-Variable Structure Adaptive Control are compared by sinusoidal response by a sinusoidal signal (amplitude: $100^{\circ}$, frequency: $2 \mathrm{~Hz}$ ) with a constant torque of $5 \mathrm{Nm}$. The experimental results are shown in Figures 26-30; Figure 26 is the position tracking curve, Figure 27 is the position tracking error curve, and Figure 28 is the speed curve. Figure 29 is the original curve of torque sensor under Fuzzy PID-Variable Structure Adaptive Control (it is basically consistent with the curve of torque sensor under PID control), and Figure 30 is the curve of torque sensor after a low-pass filter. 


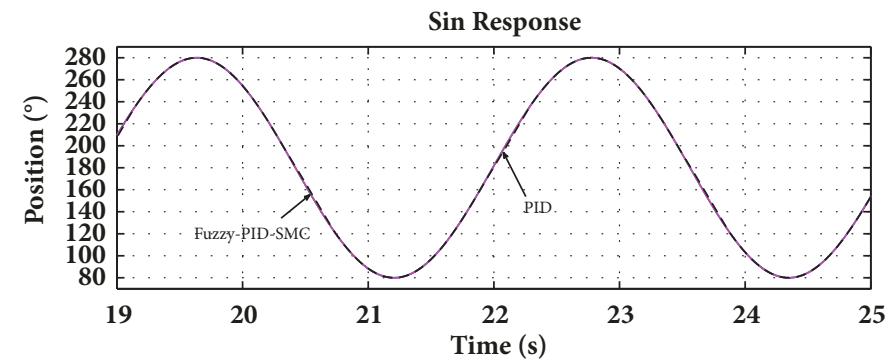

FIGURE 26: Sinusoidal response position tracking.

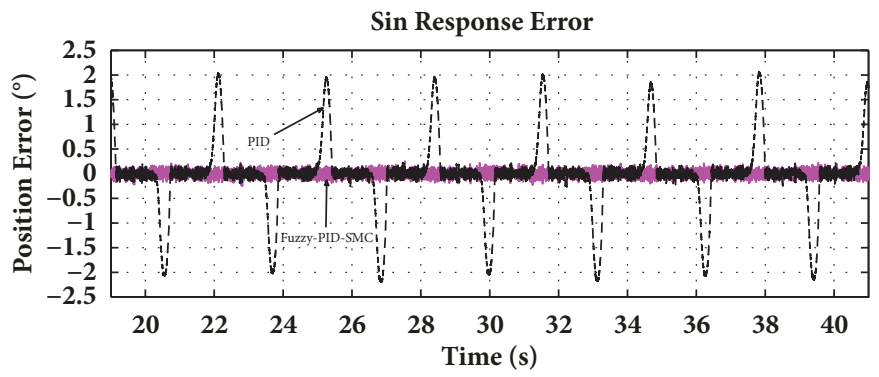

FIGURE 27: Sinusoidal response position tracking error.

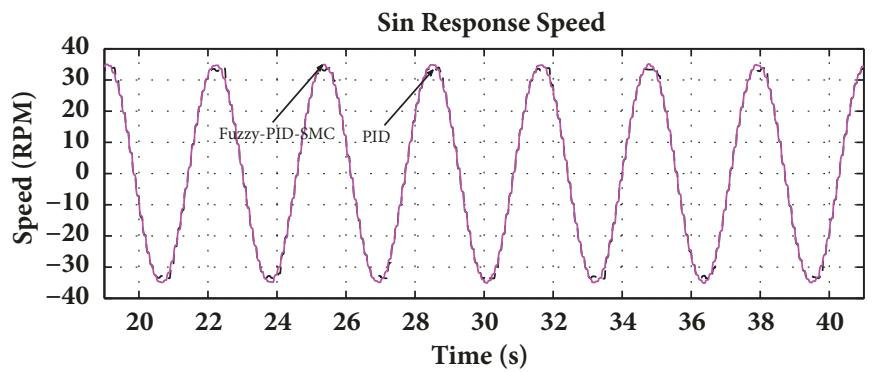

FIGURE 28: Sinusoidal response speed.

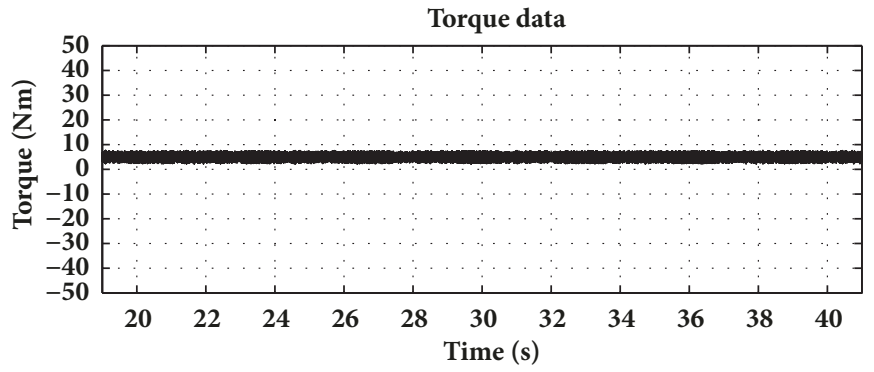

FIGURE 29: Sinusoidal response original torque data.

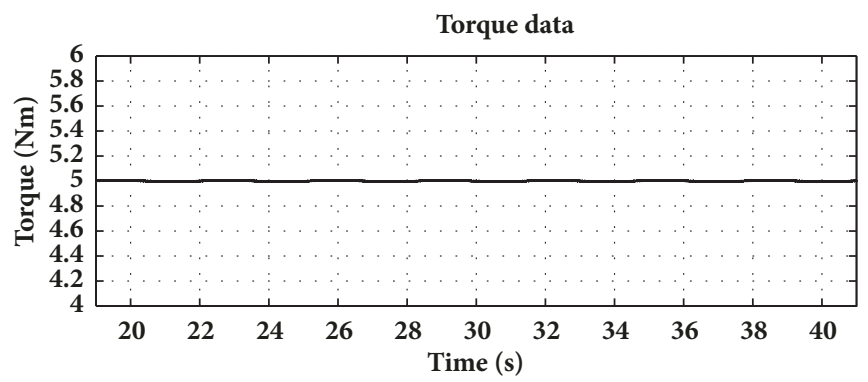

Figure 30: Sinusoidal response torque data after low-pass filter. 
Both conventional PID control and Fuzzy PID-Variable Structure Adaptive Control achieve good performances under the proper parameter as shown Figure 26. Since the conventional PID control performances are good enough, the advantages of Fuzzy PID-Variable Structure Adaptive Control will be more persuasive when we illustrate the tracking errors in Figure 27. It is observed that the dynamic response of Fuzzy PID-Variable Structure Adaptive Control outperforms that of conventional PID control, especially at the near place of the position curve crossing time axis (at this time, the speed reaches the maximum.).

There is no obvious chattering in the response curve of static testing and dynamic testing under Fuzzy PIDVariable Structure Adaptive Control, which indicates that it is feasible to introduce fuzzy inference into PID control to attenuate chattering. Finally, we conclude the advantages of the proposed Fuzzy PID-Variable Structure Adaptive Control method as high precision, good robustness, and simplicity based on experiments.

\section{Conclusion}

The Fuzzy PID-Variable Structure Adaptive Control algorithm for the position tracking control of PMSM which will be used in electric extremity exoskeleton robot is proposed. The controller consists of two parts which are mutual compensation: one is a nonlinear part (Variable structure control), and the other is an approximate linear part (fuzzy PID control). Variable structure control has high robustness. Fuzzy PID control is used to compensate the equivalent control item in SMC and attenuate chattering. The simulation results show that the algorithm can improve control accuracy, dynamic performance, and robustness. The chattering of sliding mode system is attenuated to some extent. At the same time, the Fuzzy PID-Variable Structure Adaptive Control algorithm has the advantages of simple structure and easy engineering realization as well. Finally, the effectiveness and practicability of the algorithm are verified based on a semiphysical simulation test bench with the method of RCP.

Undoubtedly, the control algorithm proposed in this paper as the lower level control method can be applied in our designed electric exoskeleton successfully. And it is also the foundation and origin of designing the higher level control method in our later works on this electric extremity exoskeleton.

\section{Data Availability}

The simulation and experimental data used to support the findings of this study are available from the corresponding author upon request.

\section{Conflicts of Interest}

The authors declare that there are no conflicts of interest regarding the publication of this paper.

\section{Acknowledgments}

This work was supported by the Chinese National Science Foundation (no. 51075017).

\section{References}

[1] X. Zhang, Z. Yue, and J. Wang, "Robotics in lower-limb rehabilitation after stroke," Behavioural Neurology, vol. 2017, Article ID 3731802, 13 pages, 2017.

[2] S. Yu, Z. Wang, and K. Zhang, "Sequential time-dependent reliability analysis for the lower extremity exoskeleton under uncertainty," Reliability Engineering \& System Safety, vol. 170, pp. 45-52, 2018.

[3] Z. Li, W. Ma, Z. Yin, and H. Guo, "Tracking control of timevarying knee exoskeleton disturbed by interaction torque," ISA Transactions $^{\circledR}$, vol. 71, pp. 458-466, 2017.

[4] B. Brahmi, M. Saad, C. Ochoa Luna, M. H. Rahman, and A. Brahmi, "Adaptive Tracking Control of an Exoskeleton robot with Uncertain Dynamics Based on Estimated Time Delay Control," IEEE/ASME Transactions on Mechatronics, 2018.

[5] Q. Wu, X. Wang, F. Du, and R. Xi, "Modeling and position control of a therapeutic exoskeleton targeting upper extremity rehabilitation," Proceedings of the Institution of Mechanical Engineers, Part C: Journal of Mechanical Engineering Science, vol. 231, no. 23, pp. 4360-4373, 2017.

[6] J. Qian, A. Xiong, and W. Ma, "Extended state observerbased sliding mode control with new reaching law for pmsm speed control," Mathematical Problems in Engineering, vol. 2016, Article ID 6058981, 10 pages, 2016.

[7] S. Wang, Y. Gao, J. Liu, and L. Wu, "Saturated sliding mode control with limited magnitude and rate," IET Control Theory \& Applications, vol. 12, no. 8, pp. 1075-1085, 2018.

[8] A. V. Topalov, G. L. Cascella, V. Giordano, F. Cupertino, and O. Kaynak, "Sliding mode neuro-adaptive control of electric drives," IEEE Transactions on Industrial Electronics, vol. 54, no. 1, pp. 671-679, 2007.

[9] J. F. Wu, J. Z. Wang, and L. P. Wang, "Adaptive fuzzy sliding mode control of asymmetrical hydraulic cylinder based on DSP," Advanced Materials Research, vol. 655, pp. 1474-1478, 2013.

[10] J. C. Zhou, J. P. Tian, and A. H. Tang, "Adaptive Sliding Mode Variable Structure Control for Turn Over Robot Based on RBF Neural Network," Automation Instrumentation, pp. 34-36, 2018.

[11] L. Qi and H. Shi, "Adaptive position tracking control of permanent magnet synchronous motor based on RBF fast terminal sliding mode control," Neurocomputing, vol. 115, pp. 23-30, 2013.

[12] F.-J. Lin and R.-J. Wai, "Sliding-mode-controlled slider-crank mechanism with fuzzy neural network," IEEE Transactions on Industrial Electronics, vol. 48, no. 1, pp. 60-70, 2001.

[13] D. X. Phu, T. D. Huy, V. Mien, and S.-B. Choi, "A new composite adaptive controller featuring the neural network and prescribed sliding surface with application to vibration control," Mechanical Systems and Signal Processing, vol. 107, pp. 409-428, 2018.

[14] T. Su, W. Kuo, V. Giap, H. Q. Vu, and Q. Nguyen, "Active Magnetic Bearing System Using PID-surface Sliding Mode Control," in Proceedings of the 2016 Third International Conference on Computing Measurement Control and Sensor Network (CMCSN), pp. 5-8, Matsue, Japan, May 2016. 
[15] Z. Tang, P. Pei, M. Wen, and Z. Shi, “Two novel reaching laws and their use in sliding mode control of EHA," in Proceedings of the 2015 IEEE International Conference on Information and Automation, ICIA 2015 - In conjunction with 2015 IEEE International Conference on Automation and Logistics, pp. 1441-1446, China, August 2015.

[16] E. M. Jafarov, M. N. A. Parlakçi, and Y. Istefanopulos, "A new variable structure PID-controller design for robot manipulators," IEEE Transactions on Control Systems Technology, vol. 13, no. 1, pp. 122-130, 2005.

[17] W. H. Jiang, Y. C. Fan, Z. Liu, and D. Zeng, "Design of servo positioning system based on PID variable structure," Applied Mechanics and Materials, vol. 321-324, pp. 1463-1467, 2013.

[18] S. Liu and L. Ding, "Application of adaptive fuzzy sliding mode controller in PMSM servo system," in Proceedings of the 1st International Conference on Computing Control and Industrial Engineering, CCIE 2010, pp. 95-98, China, June 2010.

[19] A. Ayadi, M. Smaoui, S. Aloui, S. Hajji, and M. Farza, "Adaptive sliding mode control with moving surface: Experimental validation for electropneumatic system," Mechanical Systems and Signal Processing, vol. 109, pp. 27-44, 2018.

[20] Z. M. Chen, W. J. Meng, and J. G. Wang, "Fuzzy reaching law sliding mode control of robot manipulators," IEEE PacificAsia Workshop on Computational Intelligence and Industrial Application, vol. 2, pp. 393-397, 2008.

[21] S. S. Yeoh, T. Yang, L. Tarisciotti, C. I. Hill, S. Bozhko, and P. Zanchetta, "Permanent-Magnet Machine-Based Starter-Generator System With Modulated Model Predictive Control," IEEE Transactions on Transportation Electrification, vol. 3, no. 4, pp. 878-890, 2017.

[22] C.-C. Tsai, F.-C. Tai, Y.-L. Chang, and C.-T. Tsai, "Adaptive predictive PID control using fuzzy wavelet neural networks for nonlinear discrete-time time-delay systems," International Journal of Fuzzy Systems, vol. 19, no. 6, pp. 1718-1730, 2017.

[23] A. Deep, N. K. Pilli, A. K. Chauhan, and S. K. Singh, "Design and development of rapid prototype controlled PMSM drive," in Proceedings of the 2015 IEEE IAS Joint Industrial and Commercial Power Systems / Petroleum and Chemical Industry Conference, ICPSPCIC 2015, pp. 134-139, India, November 2015.

[24] W. Zhang, Y. Zhang, R. Wang, and X. Pan, "A model-based DSP control platform for rapid prototype of SVPWM," in Proceedings of the 2010 IEEE 10th International Conference on Signal Processing, ICSP2010, pp. 2523-2526, China, October 2010 . 


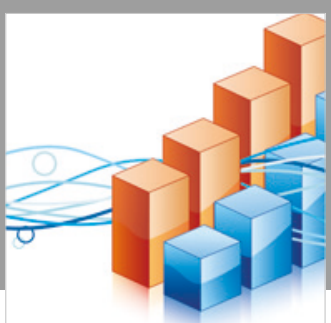

Advances in

Operations Research

\section{-n-m}
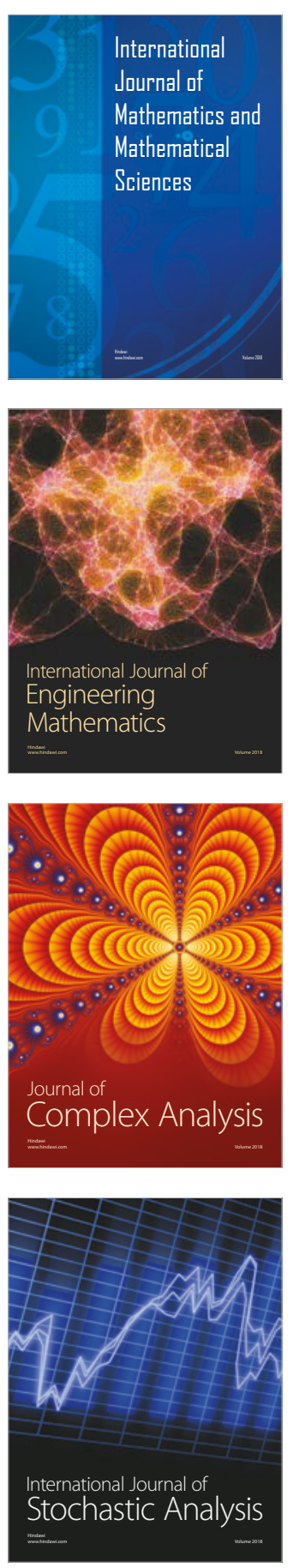
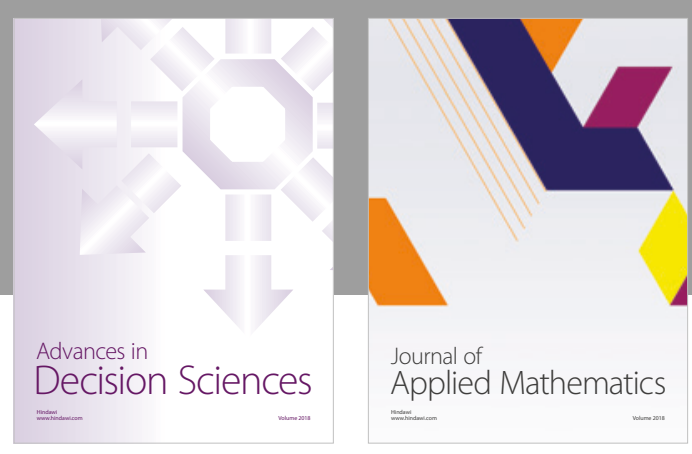

Journal of

Applied Mathematics
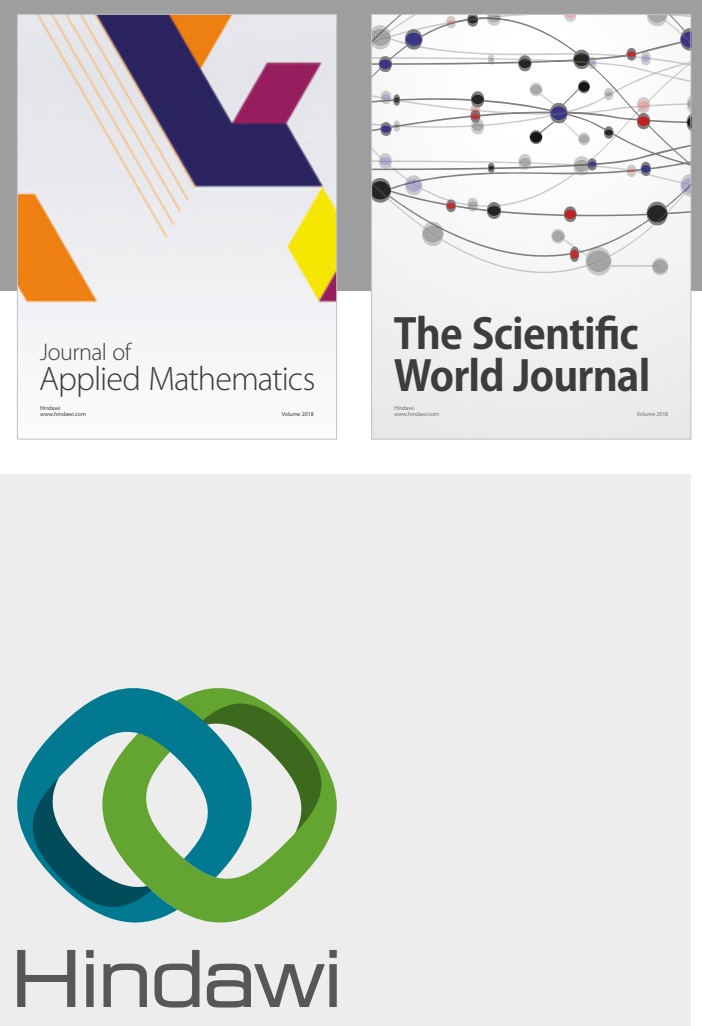

Submit your manuscripts at

www.hindawi.com

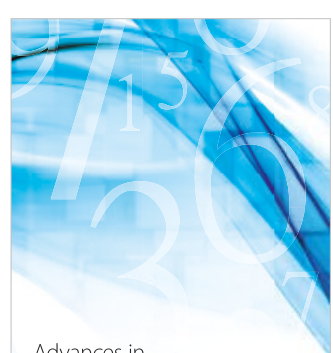

Advances in
Numerical Analysis
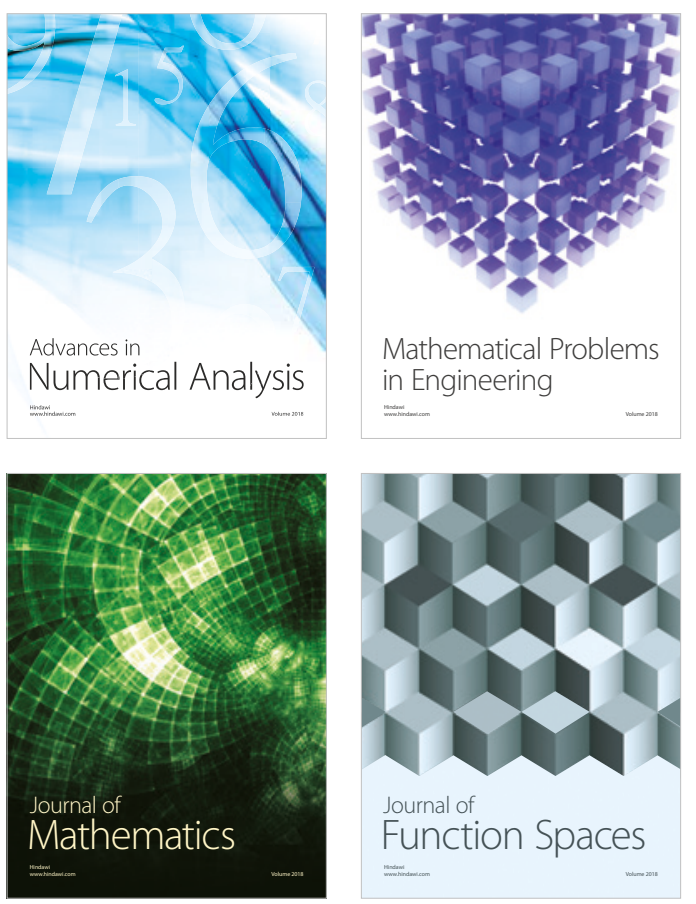

Mathematical Problems in Engineering

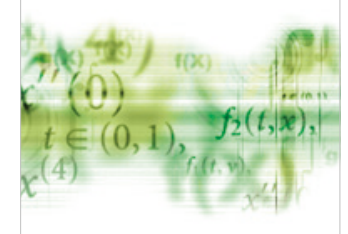

International Journal of

Differential Equations

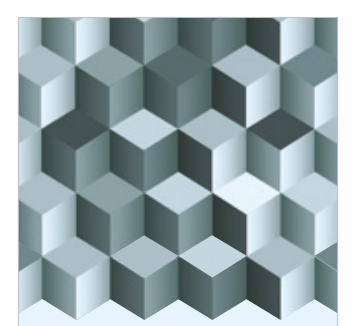

Journal of

Function Spaces
The Scientific

World Journal

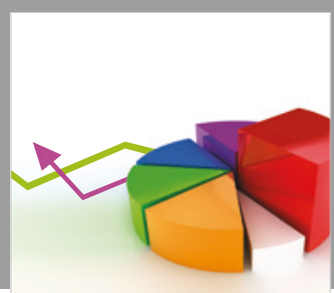

Journal of

Probability and Statistics
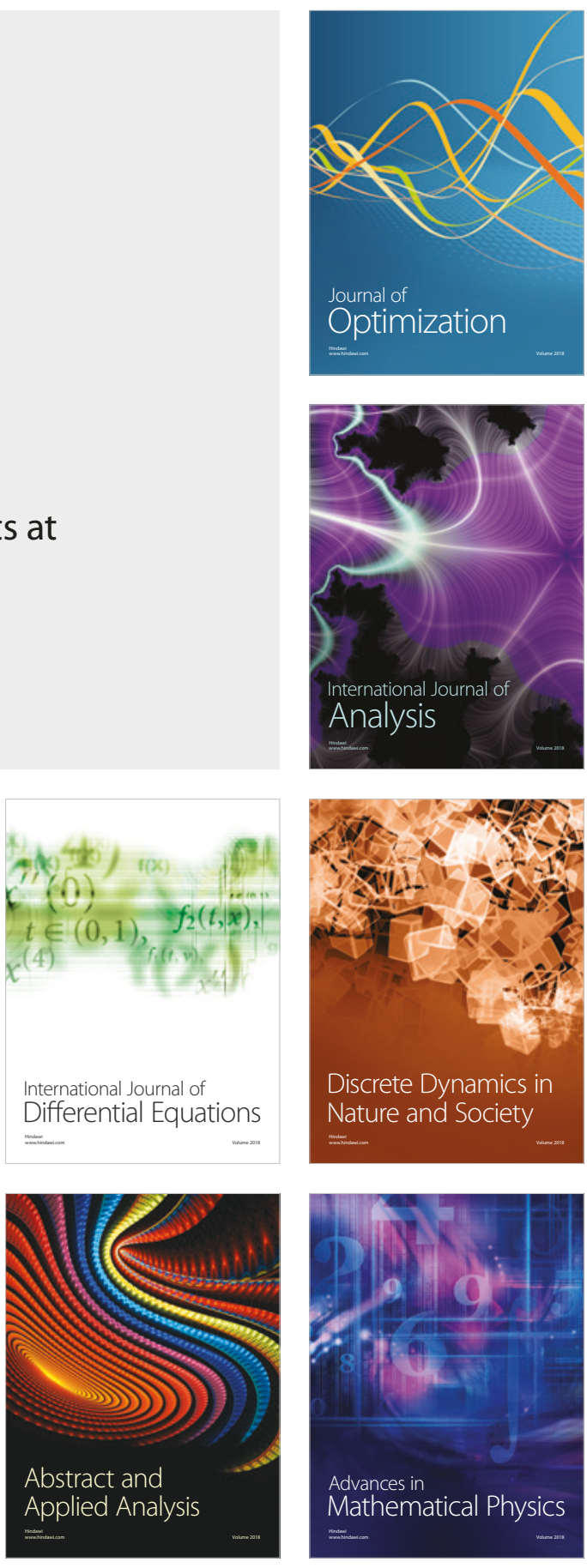